\title{
Vitamin D and Secondary Hyperparathyroidism in HIV Infected Patients Taking Antiretroviral Therapy
}

\author{
Huylmer Lucena Chaves' ${ }^{1}$ Henrique Pires Moreira1, Hayato Augusto Hossoé Corrêa ${ }^{1}$, \\ William Browne de Oliveira Machado', Rian Brito Teles ${ }^{1}$, \\ Lucigleyson Ribeiro do Nascimento', Janedson Baima Bezerra Filho', \\ Camilla Camuza Coelho Rabelo Queiroz¹, Danilo Gonçalves Nóbrega1, \\ Ana Carolina Vasconcelos Moreira1, Maria Carolina Nunes Albano de Meneses ${ }^{1}$, \\ Fabrício de Maicy Bezerra' ${ }^{1,2,3}$, Melissa Soares Medeiros ${ }^{1,2,3}$ \\ ${ }^{1}$ Medicine School, UNICHRISTUS, Fortaleza, Brazil \\ ${ }^{2}$ Fortaleza General Hospital, Fortaleza, Brazil \\ ${ }^{3}$ São Jose Hospital of Infectious Diseases, Fortaleza, Brazil \\ Email: melmedeiros@hotmail.com
}

Received 14 October 2014; revised 10 November 2014; accepted 7 December 2014

Copyright (C) 2014 by authors and Scientific Research Publishing Inc.

This work is licensed under the Creative Commons Attribution International License (CC BY).

http://creativecommons.org/licenses/by/4.0/

(c) (i) Open Access

\section{Abstract}

Objective: Due to the lack of studies assessing hypovitaminosis D and secondary hyperparathyroidism in Brazilian HIV-infected population, especially in the northeastern population, this study aimed to determine the profile of these conditions in patients infected with HIV and its correlation with immuno-virological, sociodemographic data and associated comorbidities. Methods: Comparison studies were obtained from routine clinical samples of HIV infected patients submitted for 25-OH Vitamin D, PTH and alkaline phosphatase determination. Results: A total of 78 patients were included, $42(53.8 \%)$ males, mean age 45.7 years. Antiretroviral regimens most used in this study were Zidovudine/Lamivudine/Efavirenz 17.9\%, Tenofovir/Lamivudine/Efavirenz 17.9\%, Tenofovir/Lamivudine/Atazanavir-r 15.4\%. The mean value CD4 count was $592.1 \pm 247.2 \mathrm{cells} / \mathrm{mm}^{3}$, CD8 cell count was $1026.5 \pm 467.3$ cells $/ \mathrm{mm}^{3}$, mean detectable viral load was $2220 \pm 15703$ copies and CD4/CD8 ratio was $0.63 \pm 0.33$. A total of 34 vitamin D dosages were collected with $41.2 \%$ representing sufficient amount and 58.8\% insufficient. Alkaline Phosphatase (ALP) dosage was elevated in $49.3 \%(\mathrm{~N}=35)$ of the patients. Parathormone $(\mathrm{PTH})$ was elevated in $18 \%(\mathrm{~N}=11)$. Among patients with elevated PTH levels, $81.9 \%$ had elevated levels of ALP $(p=0.01)$. In the group of patients with high levels of ALP, $45.7 \%$ had a CD4 count $<500$ cels $/ \mathrm{mm}^{3}(p=0.02)$. There was no significant difference in vitamin $D$ related to gender $(p=0.21)$, age $(p=0.23)$, CD4 count $(p=$ 0.26), suppressed viral load $(p=0.44)$ or blood glucose $(p=0.45)$. Conclusions: This study evi- 
denced a high prevalence of Vitamin D insufficiency in Northeast Brazil, which suggests HIV infection correlation. A high prevalence of Hyperparathyroidism was detected and related with inflammatory condition persistence and low CD4 count. We suggest improve vitamin D follow up and measurements in this population with better CD4 count control to avoid future osteoarticular complications of HIV treatment.

\section{Keywords}

HIV, Hyperparathyroidism, Vitamin D, Antiretroviral Therapy

\section{Introduction}

According to the United Nations Program on HIV/AIDS (UNAIDS), around 35 million people were living with HIV, 2.1 million have been infected by the virus and 1.5 million died in 2013 [1]. Brazil estimates 718,000 people living with HIV, which represents a prevalence of $0.4 \%$ in general population, but just 574,000 are diagnosed. In 2012, around 313,000 people were on antiretroviral therapy, only 44\% of people living with HIV infection [2].

Under the advent of antiretroviral therapy (ART), the number of new infected persons, the onset of opportunistic infections and mortality in HIV patients had a large reduction [3]. This view attended to new health problems in the population living with HIV, such as higher prevalence of cardiovascular diseases, diabetes mellitus [4], acute myocardial infarction [5] [6] and heart failure [7]. Besides those, disturbances such as hypovitaminosis D had been related [8] [9].

As ultraviolet B exposure varies with the latitude of regions and during the year, mean vitamin D concentrations in general populations can change. Furthermore, women and elderly people are generally more prone to low 25(OH)D concentrations, because of testosterone, less sun exposure and limited capacity of the skin to produce vitamin D metabolites. In a meta-analysis of eight prospective cohort studies, the lowest vitamin D quintile was associated with increased all-cause mortality, cardiovascular mortality, and cancer mortality [10].

Vitamin D is a steroid-derived, fat-soluble vitamin related to the modulation of immune response [11] [12]. This was demonstrated with in vitro studies in which there was maturation of monocytes, reduction in viral replication and infection of macrophages after pre-treatment with vitamin $\mathrm{D}$ [13].

The deficiency of vitamin D is markedly more frequent in patients diagnosed with HIV, especially at advanced stages, than in the general population. Studies have already showed a high prevalence of this condition among general population, as even $86.7 \%$ in Iranian one [14] [15].

Some risk factors have been established, such as nonwhite race [16], low sun exposure, use of efavirenz, metabolic syndrome [17], lactose intolerance [18], physical inactivity [19], use of ART for more than three years, low CD4 + T cells [20], high body mass index (BMI) [21] and unsuccessful viral suppression of HIV [22]. The deficiency of this compound is also related to disease progression to more advanced stages, but also association with levels of CD4 [23].

HIV is associated with a reduction in bone mineral density by generating hypovitaminosis D, through mechanisms such as induction of consumption of 25-hydroxyvitamin D by immune cells, inhibition of hydroxylation of this molecule in the kidneys and increase of TNF- $\alpha$ levels [24]. Consequently, patients with HIV are at higher risk of falls and fractures [25] [26].

As already known, it is not only the virus that causes changes in the patient. The use of ART is also related to major changes in the metabolism of calcium. Among these changes, we observed a greater tendency to osteoporosis, reduction of calcium levels, reduction of 1,25-dihydroxyvitamin D and the increase of levels of parathyroid hormone [14]. The drugs more relevant are protease inhibitors [8], reverse transcriptase inhibitor tenofovir [27] and Zidovudine, related to hypovitaminosis D [28].

Based on the risks proposed by the deficiency of vitamin D, it has been given greater attention to the use of cholecalciferol and calcium supplementation for patients with HIV, objecting a reduction in bone reabsorption and maintenance in bone mineral density [29].

In the last years we observed the increased survival of patients with HIV after the introduction of HAART, and therefore more attention has been given to long-term complications. Due to the lack of studies assessing the 
complications of hypovitaminosis D and secondary hyperparathyroidism in Brazilian HIV-infected population, especially in the northeastern population, this study aimed to determine the profile of hypovitaminosis D and secondary hyperparathyroidism in patients infected with HIV and its correlation with immuno-virological, sociodemographic data and patients comorbidities.

\section{Materials and Methods}

This was a retrospective, observational, analytical study, which included patients who are followed at the clinic in Hospital Geral de Fortaleza, Brazil. A files review of the patients diagnosed with HIV infection was conducted. Data were collected through a form containing sociodemographic, immuno-virological, antiretroviral therapy, blood glucose, vitamin D, parathyroid hormone (PTH), alkaline phosphatase (ALP), and comorbidities related, as osteoarticular diseases and tuberculosis.

Vitamin D and parathormone were detected by automated direct chemiluminescent assays. Alkaline Phosphatase Assay Kit, Kinetic Determination, was designed to measure ALP activity in biological samples. Reference values for Vitamin D were considered as hipervitaminose (>100 ng/mL), sufficiency (30 - $100 \mathrm{ng} / \mathrm{mL})$, insufficiency (30 - $10 \mathrm{ng} / \mathrm{mL})$ and deficiency $(<10 \mathrm{ng} / \mathrm{mL})$. Alkaline phosphatase normal values considered normal between 50 - 250 units per liter, and Parathormone between 16 - 87 picograms per milliliter (pg/mL).

Data were collected only after the Ethics Committee of Hospital Geral de Fortaleza has approved the study.

All results are expressed as mean and standard deviation, and submitted to D'Agostino-Pearson normality test. Comparing the groups using Student's t test complemented statistical analysis. The test is considered statistically significant if $\mathrm{p}<0.05$. Sample size $(\mathrm{N})$ is for convenience, by adding the maximum possible number of components.

\section{Results}

A total of 78 patients were included, 42 (53.8\%) males with a mean age of $45.7 \pm 11.03$ years (variance 25 - 81 ). The mean period of HIV diagnosis was $100.1 \pm 49.8$ months and the mean period of the last ART in use was $49.5 \pm 30$ months. Most of the patients were asymptomatic during clinical evaluation (69.2\%), and some had complained about articular pain (17.9\%) or lumbar pain $(12.8 \%)$.

Antiretroviral regimens most used by patients in this study were Zidovudine/Lamivudine/Efavirenz 17.9\%, Tenofovir/Lamivudine/Efavirenz 17.9\%, Tenofovir/Lamivudine/Atazanavir-r 15.4\% and Zidovudine/Lamivudine/ Atazanavir without booster $10.3 \%$, which represented $61.5 \%$ of all regimens. Just two patients were using integrase inhibitor; the others had schemes of transcriptase inhibitors and protease inhibitors associations. Patients had a diagnosis of tuberculosis associated with HIV in 10.3\%. The mean value of blood glucose levels was 104 $\pm 25 \mathrm{mg} / \mathrm{dL}$, and $46.2 \%$ of patients had blood glucose levels above $100 \mathrm{mg} / \mathrm{dL}$.

During immuno-virological evaluation the mean CD4 count was $592.1 \pm 247.2 \mathrm{cells} / \mathrm{mm}^{3}$, CD8 cell count $1026.5 \pm 467.3$ cells $/ \mathrm{mm}^{3}$, and mean detectable viral load was $2220 \pm 15,703$ copies. Analyzing CD4/CD8 ratio in the same period was $0.63 \pm 0.33$.

A total of 34 vitamin D dosages were collected with $41.2 \%$ representing sufficient amount and $58.8 \%$ insufficient. Alkaline Phosphatase (ALP) dosage was elevated 49.3\% ( $\mathrm{N}=35)$ and normal in 50.7\% $(\mathrm{N}=36)$ of the patients. Parathormone $(\mathrm{PTH})$ was elevated in $18 \%(\mathrm{~N}=11)$ and normal in $82 \%(\mathrm{~N}=50)$ patients (Table 1$)$.

Among patients with elevated PTH levels, 81.9\% had elevated levels of ALP, while in the group of patients with normal PTH levels, only 41.3\% showed increased ALP values ( $\mathrm{p}=0.01$, 95\%, CI 1.27 - 3.08, RR 1.98), (Table 2).

In the group of patients with high levels of ALP, 45.7\% had a CD4 count $<500$ cels $/ \mathrm{mm}^{3}$, while in the group with normal ALP, only 22.2\% had CD4 counts $<500$ cels $/ \mathrm{mm}^{3}$ (p = 0.02, 95\%, CI $1.01-4.18$, RR 2.05), (Table 3).

There was no significant difference in vitamin $\mathrm{D}$ related to gender $(\mathrm{p}=0.21)$, age $(\mathrm{p}=0.23)$, CD4 count $(\mathrm{p}=$ $0.26)$, suppressed viral load $(p=0.44)$ or blood glucose $(p=0.45)$.

In the group of patients with high levels of ALP, $45.7 \%$ had a CD4 count $<500$ cels $/ \mathrm{mm}^{3}$, while in the group with normal ALP, only 22.2\% had CD4 counts $<500$ cels $/ \mathrm{mm}^{3}$ (p = 0.02, 95\%, CI $1.01-4.18$, RR 2.05), (Table 3).

There was no significant difference in vitamin D related to gender $(p=0.21)$, age $(p=0.23)$, CD4 count $(p=$ $0.26)$, suppressed viral load $(p=0.44)$ or blood glucose $(p=0.45)$. 
Table 1. Dosage of Vitamin D in patients taking antiretroviral therapy related eith epidemiology and immune-virologic parameters.

\begin{tabular}{|c|c|c|c|c|c|}
\hline Vitamin D & Deficient & Insufficient & Sufficient & Hypervitamin & $\mathrm{p}$ value \\
\hline Female & 0 & 10 & 9 & 0 & \multirow{2}{*}{0.21} \\
\hline Male & 0 & 10 & 5 & 0 & \\
\hline \multicolumn{6}{|l|}{ Age (years) } \\
\hline$<50$ & 0 & 13 & 12 & 0 & 0.23 \\
\hline$\geq 50$ & 0 & 6 & 2 & 0 & \\
\hline \multicolumn{6}{|c|}{ Blood glucose (mg/dL) } \\
\hline$\leq 100$ & 0 & 11 & 8 & 0 & 0.45 \\
\hline$>100$ & 0 & 9 & 6 & 0 & \\
\hline \multicolumn{6}{|c|}{ CD4 count (cels/mm³) } \\
\hline$<500$ & 0 & 4 & 5 & 0 & 0.26 \\
\hline$\geq 500$ & 0 & 16 & 9 & 0 & \\
\hline \multicolumn{6}{|c|}{ Viral load suppression (copies) } \\
\hline$<50$ & 0 & 17 & 13 & 0 & 0.44 \\
\hline$\geq 50$ & 0 & 3 & 1 & 0 & \\
\hline \multicolumn{6}{|c|}{ Alkaline phosphatase (UI/L) } \\
\hline $50-250$ & 0 & 9 & 9 & 0 & 0.41 \\
\hline$>350$ & 0 & 6 & 5 & 0 & \\
\hline \multicolumn{6}{|l|}{ Parathormone (pg/ml) } \\
\hline Normal (16 - 87) & 0 & 13 & 10 & 0 & 0.42 \\
\hline Elevated (>87) & 0 & 2 & 3 & 0 & \\
\hline
\end{tabular}

Table 2. Parathormone in patients taking antiretroviral therapy related eith epidemiology and immune-virologic parameters.

\begin{tabular}{|c|c|c|c|}
\hline Parathormone (pg/ml) & Normal (16 - 87) & Elevated (>87) & $\mathrm{p}$ value \\
\hline Female & 23 & 5 & \multirow{2}{*}{0.48} \\
\hline Male & 27 & 6 & \\
\hline \multicolumn{4}{|l|}{ Age (years) } \\
\hline$<50$ & 37 & 8 & 0.59 \\
\hline$\geq 50$ & 13 & 3 & \\
\hline \multicolumn{4}{|l|}{ Blood glucose (mg/dL) } \\
\hline$\leq 100$ & 29 & 6 & 0.41 \\
\hline$>100$ & 21 & 5 & \\
\hline \multicolumn{4}{|l|}{ CD4 count (cels $\left./ \mathrm{mm}^{3}\right)$} \\
\hline$<500$ & 16 & 5 & 0.2 \\
\hline$\geq 500$ & 34 & 6 & \\
\hline \multicolumn{4}{|c|}{ Viral load suppression (copies) } \\
\hline$<50$ & 44 & 10 & 0.62 \\
\hline$\geq 50$ & 6 & 1 & \\
\hline \multicolumn{4}{|l|}{ Alkaline phosphatase (UI/L) } \\
\hline $50-250$ & 27 & 2 & 0.017 \\
\hline$>350$ & 19 & 9 & \\
\hline
\end{tabular}


Table 3. Alkaline phosphatase in patients taking antiretroviral therapy related eith epidemiology and immune-virologic parameters.

\begin{tabular}{|c|c|c|c|}
\hline Alkaline phosphatase (UI/L) & Normal (50 - 250) & Elevated $(>250)$ & $\mathrm{p}$ value \\
\hline Female & 20 & 14 & \multirow{2}{*}{0.1} \\
\hline Male & 16 & 21 & \\
\hline \multicolumn{4}{|l|}{ Age (years) } \\
\hline$<50$ & 27 & 24 & 0.28 \\
\hline$\geq 50$ & 9 & 11 & \\
\hline \multicolumn{4}{|l|}{ Blood glucose (mg/dL) } \\
\hline$\leq 100$ & 22 & 16 & 0.1 \\
\hline$>100$ & 14 & 19 & \\
\hline \multicolumn{4}{|l|}{ CD4 count (cels/mm³) } \\
\hline$<500$ & 8 & 16 & 0.02 \\
\hline$\geq 500$ & 28 & 19 & \\
\hline \multicolumn{4}{|l|}{ Viral load suppression (copies) } \\
\hline$<50$ & 28 & 31 & 0.25 \\
\hline$\geq 50$ & 7 & 4 & \\
\hline
\end{tabular}

\section{Discussion}

Vitamin D is actually considered as immune modulatory substance, after a discovery of specific receptors of this substance on cells of immune system, as lymphocytes and dendritic cells. In addition, a series of studies correlated their deficiency with a higher incidence of diarrhea, tuberculosis and general respiratory infections [30]. Despite a high prevalence of low vitamin D in our study, it was not correlated with symptomatic patients and even tuberculosis coinfection.

Studies conducted in different parts of the world evidenced inadequate levels of vitamin D in most patients with HIV infection, including developed countries as United States, as The Women's Interagency HIV Study (WIHS) study demonstrated a 60\% prevalence of hypovitaminosis D [14]. In the present study there was no gender related alterations in vitamin D or hyperparathyroidism, suggesting a stronger association with HIV infection as cause than gender hormone differences.

Conrado et al. (2011) [31] showed that vitamin D deficiency is higher among Brazilian population with HIV, with an incidence of approximately $40 \%$. Although vitamin D is obtained from diet and dietary supplements, the main source of vitamin D is its production in skin under the influence of solar ultraviolet B radiation. In this study, the region mean temperature during the year varies from $24^{\circ} \mathrm{C}$ to $29^{\circ} \mathrm{C}$. Despite the weather conditions being in favor of the production of vitamin $\mathrm{D}$ in northeastern Brazil due to elevated sun exposure, the prevalence of deficiency of this compound in the present study was elevated in patients with HIV surveyed in this region and reaching higher than those seen in other Brazilian studies values.

In a cohort performed by Cervero et al. (2012) [22] it was noticed that vitamin D deficiency was $16.4 \%$ more prevalent in the group with HIV. Furthermore, several factors were identified as independent risk factors for the onset of this deficiency, such as exposure to efavirenz and higher viral loads. Efavirenz is a first line drug in Brazil, as Tenofovir and Zidovudine, so a great percentage of this study population was under these drugs use, which could be an important contributing factor to vitamin D insufficiency.

The high values of PTH in patients from our study show that there is the development of secondary hyperparathyroidism in this group, being that a response for the maintenance of calcium homeostasis and reduction of the effects of hypovitaminosis D.

Several diseases and organic impairments are related to this vitamin deficiency, the most important are: changes that generate bone fragility [32], progression of Alzheimer's disease [33], diabetes [34], risk of cardiovascular diseases [35], increased risk of cancer [36] and kidney disease [37]. Besides we did not found a large correlation with comorbidities as diabetes mellitus, there is an evidence of high levels of blood glucose above 
$100 \mathrm{mg} / \mathrm{dL}$ in all population studied, suggesting insulin periphery resistance as common find.

High levels of ALP are related to increased risk for fractures and mortality from cardiac and infectious causes. These effects are independent from calcium and PTH [38]. Therefore, patients with HIV are at risk by: inflammatory process of the disease, hypovitaminosis D, elevated PTH values and also have high risk of death due to high prevalence of elevated ALP. In the present study, we observed a prevalence of low CD4 counts in patients with higher ALP values, and low ratio CD4/CD8, suggesting a persistent inflammatory response that could be contributing to vitamin D insufficiency and possible other mortality causes.

Detecting a high prevalence of this vitamin D deficiency in HIV population, organs such as the European AIDS Clinical Society (EACS) indicates following measurements of vitamin D levels in all patients with HIV and recommend replacement in cases of subnormal values [39], 2011.

This study has some limitations as small number of patients included and the lack of exams in all patients, being necessary studies including a larger number of patients to assess the impact of secondary hyperparathyroidism and increased alkaline phosphatase in patients with HIV.

\section{Conclusion}

This study evidenced a high prevalence of Vitamin D insufficiency in Northeast Brazil, which could be not related with less sun exposure but suggests HIV infection correlation. A high prevalence of Hyperparathyroidism was also detected and related with inflammatory condition persistence and low CD4 count. We suggest improve vitamin D follow up and measurements in this population with better CD4 count control to avoid future osteoarticular complications of HIV treatment.

\section{Conflict of Interest}

The authors declare no interest conflicts.

\section{References}

[1] UNAIDS Global Report. AIDS Response Progress Reporting 2013. Joint United Nations Programme on HIV/AIDS (UNAIDS), Geneva.

[2] (2013) BoletimEpidemiológico-Aids e DST, Ministério da Saúde—Secretaria de Vigilância em Saúde—Departamento de DST, Aids e Hepatites Virais.

[3] Fisher, S.D., et al. (2011) Cardiovascular Disease and Therapeutic Drug-Related Cardiovascular Consequences in HIV-Infected Patients. American Journal of Cardiovascular Drugs, 11, 383-394. http://dx.doi.org/10.2165/11594590-000000000-00000

[4] Butt, A.A., et al. (2009) HIV Infection and the Risk of Diabetes Mellitus. AIDS, 23, 1227-1234. http://dx.doi.org/10.1097/QAD.0b013e32832bd7af

[5] O’Halloran, J.A., Satchell, C.S. and Mallon, P.W.G. (2013) Dyslipidemia, Atherosclerosis and Cardiovascular Disease: An Increasingly Important Triad in an Aging Population Living with HIV. Future Virology, 8, 1021-1034. http://dx.doi.org/10.2217/fvl.13.87

[6] Duprez, D.A., et al. (2012) Inflammation, Coagulation and Cardiovascular Disease in HIV-Infected Individuals. PLoS One, 7.

[7] Fisher, S.D. and Lipshultz, S.E. (2011) Chapter 72: Cardiovascular Abnormalities in HIV-Infected Individuals. In: Bonow, R.O., et al., Eds., Braunwald’s Heart Disease: A Textbook of Cardiovascular Medicine, 9th Edition, Elsevier Saunders, Philadelphia, 1618-1627.

[8] Brown, T.T. and Qaqish, R.B. (2006) Antiretroviral Therapy and the Prevalence of Osteopenia and Osteoporosis: A Meta-Analytic Review. AIDS, 20, 2165-2174. http://dx.doi.org/10.1097/QAD.0b013e32801022eb

[9] García Aparicio, A.M., et al. (2006) Abnormalities in the Bone Mineral Metabolism in HIV-Infected Patients. Clinical Rheumatology, 25, 537-539.

[10] Schöttker, B., Jorde, R., Peasey, A., et al. (2014) Consortium on Health and Ageing: Network of Cohorts in Europe and the United States (CHANCES). Vitamin D and Mortality: Meta-Analysis of Individual Participant Data from a Large Consortium of Cohort Studies from Europe and the United States. BMJ, 348.

[11] Negredo, E., Puig, J., Bonjoch, A., Pérez-Alvárez, N., Echeverría, P., Estany, C., et al. (2012) Similarly High Prevalence of Hypovitaminosis D in HIV-Infected Subjects with and without Low Bone Mineral Density. Future Virology, 7, 1127-1134. http://dx.doi.org/10.2217/fvl.12.102 
[12] Mehta, S., Spiegelman, D., Aboud, S., Giovannucci, E.L., Msamanga, G.I., Hertzmark, E., et al. (2010) Lipid-Soluble Vitamins A, D, and E in HIV-Infected Pregnant Women in Tanzania. European Journal of Clinical Nutrition, 64, 808817.

[13] Connor, R.I. and Rigby, W.F. (1991) 1-Alpha, 25-Dihydroxyvitamin D3 Inhibits Productive Infection of Human Monocytes by HIV-1. Biochemical and Biophysical Research Communications, 176, 852-859.

[14] Tafazoli, A. and Khalili, H. (2013) Vitamin D and HIV Infection: A Review of the Clinical Evidence. Future Virology, 8, 589-606. http://dx.doi.org/10.2217/fvl.13.40

[15] Legeai, C., Vigouroux, C., Souberbielle, J.-C., Bouchaud, O., Boufassa, F., Bastard, J.-P., et al. (2013) Associations between 25-Hydroxyvitamin D and Immunologic, Metabolic, Inflammatory Markers in Treatment-Naive HIV-Infected Persons: The ANRS CO9 “COPANA” Cohort Study. PLoS ONE, 8, e74868.

[16] Wasserman, P. and Rubin, D.S. (2010) Highly Prevalent Vitamin D Deficiency and Insufficiency in an Urban Cohort of HIV-Infected Men under Care. AIDS Patient Care STDS, 24, 223-227. http://dx.doi.org/10.1089/apc.2009.0241

[17] Conrado, T., Miranda-Filho, D.B. and Bandeira, F. (2010) Vitamin D Deficiency in HIV-Infected Individuals: One More Risk Factor for Bone Loss and Cardiovascular Disease? Arquivos Brasileiros de Endocrinologia e Metabologia, 54, 118-122.

[18] Rodríguez, M., Daniels, B., Gunawardene, S. and Robbins, G.K. (2009) High Frequency of Vitamin D Deficiency in Ambulatory HIV-Positive Patients. AIDS Research and Human Retroviruses, 25, 9-14.

[19] Dao, C.N., Patel, P., Overton, E.T., Rhame, F., Pals, S.L., Johnson, C., et al. (2011) Low Vitamin D among HIV Infected Adults: Prevalence of and Risk Factors for Low Vitamin D Levels in a Cohort of HIV Infected Adults and Comparison to Prevalence among Adults in the US General Population. Clinical Infectious Diseases, 52, 396-405.

[20] Stein, E.M., Yin, M.T., McMahon, D.J., Shu, A., Zhang, C.A., Ferris, D.C., et al. (2011) Vitamin D Deficiency in HIV-Infected Postmenopausal Hispanic and African-American Women. Osteoporosis International, 22, 477-487. http://dx.doi.org/10.1007/s00198-010-1299-x

[21] Adeyemi, O.M., Agniel, D., French, A.L., Tien, P.C., Weber, K., Glesby, M.J., et al. (2011) Vitamin D Deficiency in HIV-Infected and HIV-Uninfected Women in the United States. Journal of Acquired Immune Deficiency Syndromes and Human Retrovirology, 57, 197-204.

[22] Cervero, M., Agud, J.L., García-Lacalle, C., Alcázar, V., Torres, R., Jusdado, J.J. and Moreno, G.S. (2012) Prevalence of Vitamin D Deficiency and Itsrelated Risk Factor in a Spanish Cohort of Adult HIV-Infected Patients: Effects of Antiretroviral Therapy. AIDS Research and Human Retroviruses, 28, 963-971.

[23] Sudfeld, C.R., Wang, M., Aboud, S., Giovannucci, E.L., Mugusi, F.M. and Fawzi, W.W. (2012) Vitamin D and HIV Progression among Tanzanian Adults Initiating Antiretroviral Therapy. PLoS ONE, 7, e40036.

[24] Mansky K.C. (2010) Aging, Human Immunodeficiency Virus, and Bone Health. Clinical Interventions in Aging, 5, 285-292.

[25] Ansemant, T., Mahy, S., Piroth, C., Ornetti, P., Ewing, S., Guilland, J.-C., et al. (2013) Severe Hypovitaminosis D Correlates with Increased Inflammatory Markers in HIV Infected Patients. BMC Infectious Diseases, 13, 7. http://dx.doi.org/10.1186/1471-2334-13-7

[26] Conesa-Botella, A., Florence, E., Lynen, L., Colebunders, R., Menten, J. and Moreno-Reyes, R. (2010) Decrease of Vitamin D Concentration in Patients with HIV Infection on a Non-Nucleoside Reverse Transcriptase Inhibitor-Containing Regimen. AIDS Research and Therapy, 7, 40-45. http://dx.doi.org/10.1186/1742-6405-7-40

[27] Klassen, K., Martineau, A.R., Wilkinson, R.J., Cooke, G., Courtney, A.P. and Hickson, M. (2012) The Effect of Tenofovir on Vitamin D Metabolism in HIV-Infected Adults Is Dependent on Sex and Ethnicity. PLoS ONE, 7, e44845.

[28] Van Vonderen, M.G.A., Lips, P., van Agtmael, M.A., Hassink, E.A.M., Brinkman, K., Geerlings, S.E., et al. (2009) First Line Zidovudine/Lamivudine/Lopinavir/Ritonavir Leads to Greater Bone Loss Compared to Nevirapine/Lopinavir/Ritonavir. AIDS, 23, 1367-1376. http://dx.doi.org/10.1097/QAD.0b013e32832c4947

[29] Holick, M.F. et al. (2011) Evaluation, Treatment, and Prevention of Vitamin D Deficiency: An Endocrine Society Clinical Practice Guideline. Journal of Clinical Endocrinology \& Metabolism, 96, 1911-1930.

[30] Villamor, E. (2006) A Potential Role for Vitamin D on HIV Infection? Nutrition Reviews, 64, 226-233.

[31] Conrado, T., Miranda-Filho, D.B., Ximenes, R.A.A., Albuquerque, M.F., Lacerda, H.R., Ramos, R.C.F., et al. (2011) Vitamin D Deficiency in HIV-Infected Women on Antiretroviral Therapy Living in the Tropics. Journal of the International Association of Physicians in AIDS Care, 10, 239-245. http://dx.doi.org/10.1177/1545109711399657

[32] Daeson-Hughes, B., Harris, S.S., Krall, E.A. and Dallal, G.E. (1997) Effect of Calcium and Vitamin D Supplementation on Bone Density in Men and Women 65 Years of Age or Older. New England Journal of Medicine, 337, 670-676. http://dx.doi.org/10.1056/NEJM199709043371003

[33] Evatt, M.L., Delong, M.R., Khazai, N., Rosen, A., Triche, S. and Tangpricha, V. (2008) Prevalence of Vitamin D In- 
sufficiency in Patients with Parkinson Disease and Alzheimer Disease. Archives of Neurology, 65, 1348-1352. http://dx.doi.org/10.1001/archneur.65.10.1348

[34] Pittas, A.G., Dawson-Hughes, B., Li, T., Van Dam, R.M., Willett, W.C., Manson, J.E. and Hu, F.B. (2006) Vitamin D and Calcium Intake in Relation to Type 2 Diabetes in Women. Diabetes Care, 29, 650-656. http://dx.doi.org/10.2337/diacare.29.03.06.dc05-1961

[35] Pérez-López, F.R. (2009) Vitamin D Metabolism and Cardiovascular Risk Factors in Postmenopausal Women. Maturitas, 62, 248-262. http://dx.doi.org/10.1016/j.maturitas.2008.12.020

[36] Giovannucci, E., Liu, Y., Rimm, E.B., Hollis, B.W., Fuchs, C.S., Stampfer, M.J. and Willett, W.C. (2006) Prospective Study of Predictors of Vitamin D Status and Cancer Incidence and Mortality in Men. Journal of the National Cancer Institute, 98, 451-459. http://dx.doi.org/10.1093/jnci/dji101

[37] Canale, D., de Bragança, A.C., Gonçalves, J.G., Shimizu, M.H.M., Sanches, T.R., Andrade, L., et al. (2014) Vitamin D Deficiency Aggravates Nephrotoxicity, Hypertension and Dyslipidemia Caused by Tenofovir: Role of Oxidative Stress and Renin-Angiotensin System. PLoS ONE, 9, e103055.

[38] Blayney, M.J., Pisoni, R.L., Bragg-Gresham, J.L., Bommer, J., Piera, L., Saito, A., et al. (2008) High Alkaline Phosphatase Levels in Hemodialysis Patients Are Associated with Higher Risk of Hospitalization and Death. Kidney International, 74, 655-663.

[39] Overton, E.T. and Yin, M.T. (2011) The Rapidly Evolving Research on Vitamin D among HIV-Infected Populations. Current Infectious Disease Reports, 13, 83-93. 
Scientific Research Publishing (SCIRP) is one of the largest Open Access journal publishers. It is currently publishing more than 200 open access, online, peer-reviewed journals covering a wide range of academic disciplines. SCIRP serves the worldwide academic communities and contributes to the progress and application of science with its publication.

Other selected journals from SCIRP are listed as below. Submit your manuscript to us via either submit@scirp.org or Online Submission Portal.
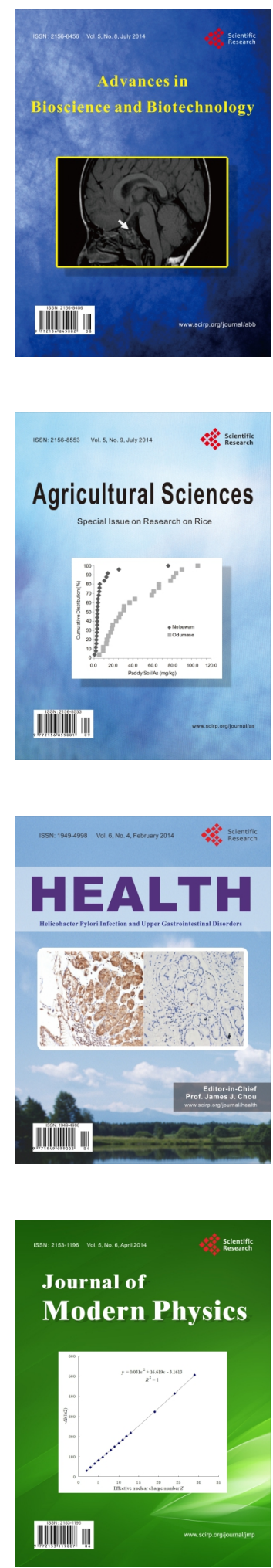
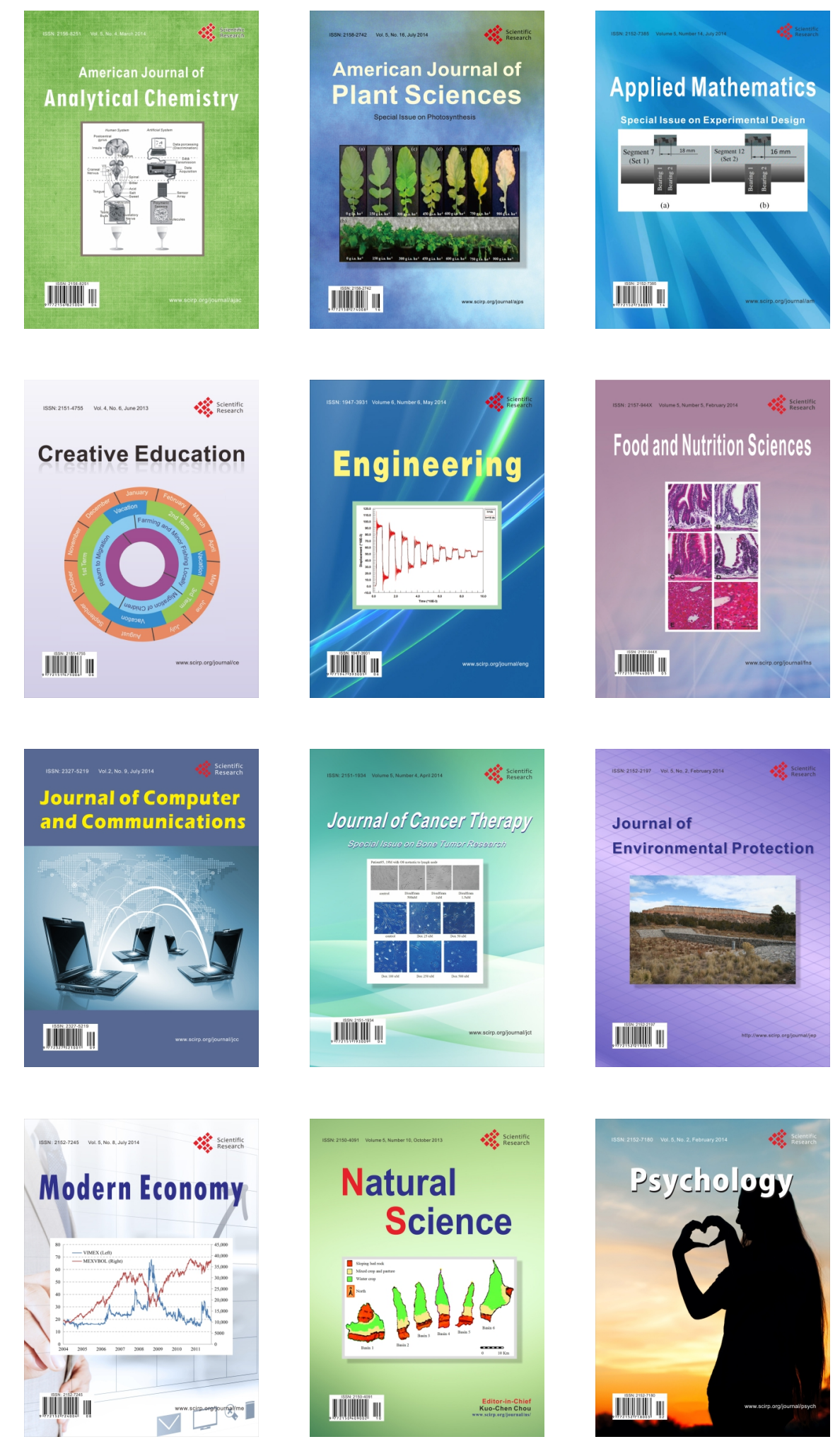